\title{
The Conception of Humanitarian Oriented Mathematics Teaching
}

\author{
Aslanbek Naziev
}

\begin{abstract}
By the conception of teaching of something we mean the system of clauses that give answers to the "three main questions of pedagogy": what? what for? how? In the case of mathematics: what is mathematics? what is mathematics for in education? how to teach mathematics? Or, in slightly different formulation: what is mathematics? what does it mean to teach mathematics? why do we need to teach mathematics? Our answers to these questions form our.

Conception of humanitarian oriented mathematics teaching:

1. Mathematics is proof;

2. To teach mathematics means to stimulate systematically the pupils to discovery of their own proofs;

3. Mathematics teaching is indispensable tool for building of homo cultural: thinking, moral and free.

In the rest of our paper we examine and prove these suggestions. In particular, we explain why we call our conception the conception of humanitarianly oriented mathematics teaching and notice connections of this conception with Polya's definition of mathematics (given in his remarkable book "Mathematical discovery") and Spenser's definition of teaching.
\end{abstract}

Index Terms - Education, culture, freedom, mathematics, teaching.

\section{HEGEL'S CONCEPTION OF EDUCATION}

$\mathrm{H}$ egel examines the notion of education in his work "Philosophical Propaedeutic" [7]. This examination he included in the part of his work named "Duties of the Individual to Himself' (sic!). Let us quote.

Duties of the Individual to Himself

Man, as an individual, stands in relation to himself. He has two aspects: his individuality and his universal essence. His Duty to Himself consists partly in his duty to care for his physical preservation, partly in his duty to educate himself, to elevate his being as an individual into conformity with his universal nature.

Underline:

1) not to receive education, but to educate himself;

2) to educate himself is its duty;

3) this is duty of individual to himself;

4) to educate himself means to elevate, not to receive;

Manuscript received February 20, 2017.

Author is with the Ryazan State University, Ryazan, 390048, Russian Federation (e-mail: a.naziev@ rsu.edu.ru).
5) to elevate into conformity with his universal nature.

Compare this goal,

to elevate man's being as an individual into conformity with his universal nature,

with another goal,

all-rounded development of personality,

which was considered as the main goal of general education in the USSR and Russia. One could think that these two goals are identical. But those who are acquainted with set theory easily will see the difference. From the set-theoretical point of view, all-roundedness corresponds to the operation of the union while universal human nature (all-humanness) - to that of the intersection. And Hegel is talking about the intersection, not about the union. General education must care about qualities common to all people. Isn't it clear? We must live in community, so the main our care must be about what is common to all members of the community. Our individual differences are our own business rather than that of general education.

In the literature were already mentioned some defects of allrounded development as a goal of general education:

1) it is non-historic;

2) it non-realistic (it is not real to develop all sides of personality particularly because not all of them are known) and

3 ) it is non-verifiable (it is impossible to verify whether all sides of personality were developed or not).

But we can add to this list of defects one more defect, more significant than all mentioned:

4) This goal is dangerous, both to individual and to the community.

Remember: several years ago almost every week we learned about new discoveries on the human gene map. We learned then that there exists the gen of alcoholism, the gen of cruelty, the gen of suicide...And this means that there exist people having the genetic predisposition to alcoholism, to cruelty, to suicide...Can we, after learning all of that, proclaim as before all-rounded development of personality the main goal of general education? No! Quite the reverse, we must hardly think which sides of individuality is worth to develop and which is not.

Thus, we see that Hegel was much more penetrating and more far-seeing than we are. Abilities, he said, one must elevate rather than develop, and elevate not in the direction of our please but in the direction of all-human nature. 
Now the question arises naturally: what is this all-human nature? There exist different answers to this question but most of the thinkers believe that this is reasonableness (the presence of reason, of mind, of intellect, ability to think, rationality). According to this point of view (and to Hegel)

education is elevation to the reasonableness,

or, as Hegel hims elf wrote,

making man's rational side become his guiding principle.

Continue quoting (ibid):

Explanatory: Man is, on the one hand, a natural being... Secondly, he is a spiritual, rational being and as such he is not by nature what he ought to be. The animal stands in no need of education, for it is by nature what it ought to be. It is only a natural being. But man has the task of bringing into harmony his two sides, of making his individuality conform to his rational side or of making the latter become his guiding principle.

The Vocation is something universal and necessary, and constitutes a side of the social life of humanity. It is, therefore, one of the divisions of human labor. When a man has a Vocation, he enters into cooperation and participation with the Whole. Through this he becomes objective. The Vocation is a particular, limited sphere, yet it constitutes a necessary part of the whole, and, besides this, is in-itself a whole. If a man is to become something he must know how to limit himself, that is, make some specialty his Vocation. Then his work ceases to be an irksome restraint to him. He then comes to be at unity with himself, with his externality, with his sphere. He is a universal, a whole.

Let us underline one more thought of Hegel:

If a man is to become something he must know how to limit himself

Turn attention: not to emancipate, but to limit!

Because this is written while considering the notion of education, it shows that the notion of education is in close connection with the two other sides of human community: that of culture and that of human freedom.

Now we turn to the consideration of these two phenomena (in their connection with that of education, naturally).

\section{SCHWEITZER'S CONCEPTION OF CULTURE}

What is culture? - It is highly surprisingly that the first (and, in our opinion, the most deep) investigation of the notion of culture was made only at the end of the first quarter of 20 century. It was made by Albert Schweitzer in his remarkable work "Kulturphilosophie" [12].

In the following citations, one must take into account that Schweitzer himself in his 1923 German edition speaks about 'Kultur' while his English trans lator uses words 'civilization' and 'progress'. According to Schweitzer,

Civilization (read: culture) is ...twofold in its nature: it realizes itself in the supremacy of reason, first, over the forces of nature, and, secondly, over the dispositions of men.

Which of these two addenda of civilization (culture) is more significant? The latter, though it is the least open to observation. Why? Because the supremacy of reason over the forces of nature can lead mankind to the situation in which men and whole nations will have abilities to destroy each other, and then only supremacy of reason over dispositions of men will give to mankind a chance to prevent the catastrophe.

This latter and most significant addendum of culture is naturally to call spiritual culture (while the former - material culture). So, according to Schweitzer,

spiritual culture is the supremacy of the reason over the disposition of men.

Noting that

the supremacy of the reas on over the disposition of men

is identical with Hegel's

making man's rational side become his guiding principle

(what Hegel called education) we can say:

education is the formation of the spiritual culture of personality,

that is, the supremacy of the reason over the disposition of men.

\section{SOCRATES' CONCEPTION OF HUMAN FREEDOM}

Now consider the role of education in the solution of one more problem of importance: the problem of human freedom.

Many people do not see here any problem. They merely think that freedom consists in the absence of limitations. But already Socrates called the man fulfilling all his desires not free but slave - slave of his wishes. Actually, the absence of limitations is by no means freedom but its ugly opposite. Genuine freedom is inconceivable without limitations. Every task requires applying of concentrated efforts in the necessary direction and therefore cutting off all that prevents to applying of these efforts. About this excellently said Austrian writer Ilse Aichinger in her remarkable story "Bound man" [1] (in the essence, repeating in art form the cited earlier words of Hegel about Vocation):

...flying is possible only for those who keep himself in a check. ...bonds rescue from the fatal advantage of free limbs which causes men to be worsted.

Serious reflections about freedom frequently are substituted by emotions. "Why God did not give us the freedom to fly as birds?" But is it the real limitation of human freedom? No! Man is not the bird, he needs human freedom, not that of the bird.

It follows, one must distinguish between the freedom of bird, the freedom of cattle, the freedom of man. So, what does it mean to be free man?

To find the answer to this question, let us first think about the bird. It is clear that bird's freedom consists in the living without limitations (yes, without limitations, but:) according to the bird's nature. Analogously, cattle's freedom consists in living without limitations accordingly cattle's nature (manifestations of this cattle's freedom by humanoids are every day demonstrated on the TV screen). And precisely in that manner the human freedom consists in living without 
limitations according to the human nature. This nature, as we have already seen, consists in spiritual culture, that is, in the supremacy of the reason over the disposition of men. So,

human freedom consists in ability to be guided, without limitations, by reason in beliefs and intensions.

Remembering what is said earlier about education, we see that the main goal of education may also be expressed as follows:

to educate means to teach human being to be the free man.

Take into account: human beings must learn to human freedom and they can learn this in the only one way - by developing in themselves the ability to subordinate their beliefs and intensions to the voice of the reason.

\section{HUMANIT ARIAN EDUCATION = EDUCATION}

English "humanitarian" has its origin in Latinas "humanitas" that means "human nature". And because education always means human education, it must be built in accordance with the human nature, that is, to be humanitarian. Of course, there may be schools and classes of biological, chemical, mathematical and other profiles, but teaching in all of them must be performed in accordance with the human nature, that is, to be humanitarian. So,

Humanitarian education is merely education, that is, elevation to the spiritual culture,

that is,

elevation to the supremacy of the reason over human convictions, intensions and believes,

that is,

making man's rational side become his guiding principle.

\section{WHAT IS MATHEMATICS?}

Mathematics, contrary to other sciences, can be characterized from the two points of view.

\section{A. Mathematics from the point of view of matter}

From the point of view of matter

Mathematics is the science of quantitative relations and spatial forms in the real world.

Quantitative relations (in the general philosophical sense of this term) are characterized, contrary to qualitative, only by their indifference to the specific nature of those objects, they relate.

$\ldots$ in the indicated general sense, all relations learned by mathematics always are quantitative [8].

This leads us to the following remarkable definition of mathematics known as earlier as VI century AD:

Mathematics is the science of abstract quantity. And abstract quantity is what we learn purely speculatively distracting it in mind from the substance and random manifestations [5].

Surely, this is the best definition of mathematics from the point of view of matter.

Now, turn to the consideration of

\section{B. Mathematics from the point of view of method}

Abstract character of mathematics predetermines the special role of the proof in it. Because of all objects of mathematics are abstract, all truths about them can be established only mentally, with the help of special mental constructions named reasoning. Reasoning convincing in the truthfulness of proposition is called proof of the proposition. Mathematics is the only science in which truth may only be established by means of proof. This leads to the definition of mathematics from the point of view of method.

Mathematics is proof.

Since the time of the Greeks to say "mathematics" means to say "proof" [4].

... mathematics is coextensive with demonstrative reasoning, which pervades the sciences just as far as their concepts are raised to a sufficiently abstract and definite mathematicallylogical level [9].

Why proofs inside mathematics?

In fact, why proofs? Why not allow to students to believe the teacher? - The point is that the confirmation of propositions is not the only intention of proof. It has at least two other intentions inside mathematics (and a large amount of intensions in education; some of them will be considered below). Namely, proof helps us to discover the truth and to understand it. Let us illustrate this by the following example.

EXAMPLE: Draw the locus of the points from the plane $O x y$ for which $\frac{1}{x}<\frac{1}{y}$.

SOLUTION. For all $\mathrm{x}$ and $\mathrm{y}$ from $\mathrm{R}$ we have:

$$
\begin{aligned}
\frac{1}{x}<\frac{1}{y} & \Longleftrightarrow \frac{1}{x}-1 y<0 \\
& \Longleftrightarrow \frac{y-x}{x y}<0 \\
& \Longleftrightarrow\left\{\begin{array} { l } 
{ y - x < 0 , } \\
{ x y > 0 ; }
\end{array} \text { or } \left\{\begin{array}{l}
y-x>0, \\
x y<0 ;
\end{array}\right.\right. \\
& \Longleftrightarrow\left\{\begin{array} { l } 
{ y < x , } \\
{ x y > 0 ; }
\end{array} \text { or } \left\{\begin{array}{l}
y>x, \\
x y<0 .
\end{array}\right.\right.
\end{aligned}
$$

Now we see: in order to represent the given set, we need to take all points with $y<x$ from the domain where $x y>0$ and add to them all points with $y>x$ from the domain where $x y<0$.

So, we understand what the given set is. How it has happened? We learn it from the text written above. What is this text? It is a proof. The proof of what is it? It is the proof of the assertion that the inequality at the beginning of the chain of equivalencies and the disjunction at the end of it are equivalent. But is it true? Of course, this text is a proof!

We see: with the help of the proof we 1) discovered the equivalence of the mentioned propositions, we 2) confirm our discovery and 3) we understand what the given set is.

Let us peak out:

THREE INTENTIONS OF THE PROOF INSIDE MATHEMATICS:

- to lead to discovery, 
- to help to understand the discovery, and

- to confirm the discovery.

VI. What Does It Mean To Teach Mathematics?

Remember Herbert Spencer (quoted from Polya [9]):

What does it mean to teach? - This means to stimulate systematically the students to their own discoveries.

Now, about mathematics we said that it is the proof. Combining these two formulations we get second proposition in our conception:

to teach mathematics means to stimulate systematically the students to the discovery of their own proofs.

\section{WHAT IS MATHEMATICS FOR IN GENERAL EDUCATION?}

\section{A. Case With Hobbes}

Remember what tell us Hegel and Schweitzer:

education consists in making man's rational side the guiding principle, or in elevation to the supremacy of the reason over human convictions, intensions and believes.

Now ask: what can mathematics give to education? To understand this, the following example will help us. John Aubrey wrote about Thomas Hobbes [3]:

He was 40 years old before he looked on geometry; which happened accidentally. Being in a gentleman's library, Euclid's Elements lay open, and "twas the 47 El. libri I" [Pythagoras' Theo- rem]. He read the proposition. "By God", said he, "this is impossible". So he reads the demonstration of it, which referred him back to such a proposition; which proposition he read. That referred him back to another, which he also read. Et sic deinceps, that at last he was demonstratively convinced of that truth. This made him in love with geometry [6].

What has happened with Hobbes in this episode? At the beginning he has one conviction but under influence of the proof his conviction became another. The proof forced him to subordinate his conviction to the voice of the reason. Such influence has every proof that we discover or understand: the proof teaches us to subordinate our intentions and convictions to the voice of the reason. This shows that mathematics, as an educational discipline, is, grinded by centuries, sys- tem of excellently selected exercises accustoming the men to supremacy of his reason over his convictions, beliefs and intensions. Namely this is the main reason for inclusion of mathematics into general education.

\section{Two Quotes From J. W. A. Young [12]}

All thinking and all actions are influenced by conclusions that have been consciously or unconsciously drawn. This fact is fundamental; if it is not habitually well done, whatever edifice of culture may be built is warped and insecure. The conclusions which must be made by the score every day are of complicated nature; the facts are so many, so elaborate, so imperfectly known, that it is often very difficult to draw any conclusion, much less to be sure that we have the right one.
It is justly demanded that the school familiarize children with a mode of thought so ubiquitous, so important and so difficult. A subject suitable for this purpose should have three characteristics:

1. That its conclusions are certain. At first, at least, it is essential that the learner should know whether or not he has drawn the correct conclusion.

2. . That it permit the learner to begin with simple and very easy conclusions, and to pass in well graded sequence to very difficult ones, as the earlier ones are mastered.

3. That the type of conclusions exemplified in the introductory subject be found in other subjects also, and in human intercourse in general.

These desiderata are possessed by mathematics in a far larger measure than by any other available subject.

And further:

Are you to be a lawyer? How can you learn to analyze a complicated legal case, if you cannot learn to analyze a simple proposition of geometry?

Are you a student of history? How can you determine the influence of Napoleon on the world's development, if you are incapable of determining the influence of a coefficient in a simple relation of algebra?

Are you a linguist? How will you translate a masterpiece, with its myriad shades of meaning, from one language into another, if you can- not learn to translate a trifling "reading problem" into the corresponding mathematical symbols?

Are you to be a physician? How will you diagnose and eliminate a disease, with its complicated, ambiguous, and obscure symptoms, if you lack the faculties needed to diagnose and eliminate the unknown quantity out of an elementary equation?

Conclusion:

in mathematics, in the pure form and in the simplest situations, are worked out such thinking skills that will be necessary to every man on every field of activity.

\section{MORAL EDUCATION AND MATHEMATICS TEACHING}

The working definition of morality was discovered - can you imagine? - in the second half of 20 century only. This was done by Russian mathematician (sic!) A. D. Aleksandrov [2].

Morality, said Aleksandrov, may be defined in short as an organic compound of the three components: humanity, responsibility and devotion to the truth.

Perhaps, one can argue whether all is taken into account in this definition, but, probably, no one would deny that these qualities are essential components of morality. Let's make sure, that the learning of mathematics decisively contributes to the formation and development of each of these three qualities.

With the devotion to the truth everything is pretty obvious. To be devoted to the truth, it is necessary first of all, to know the truth. But what means 'to know'? - 'To know' means

'to be convinced with the help of proof' (Aristotle).

So, devotion to truth involves the need for the proof that just is formed during mathematics teaching. Thus, the last of 
the components of morality is directly connected with the need of proofs forming while teaching mathematics.

Responsibility, in short, is performing of commitments. Clearly, it is inconceivable without the habit of man to constantly make sure that his words and deeds comply with these obligations, that is, explicitly or implicitly, to prove to him- self that this correspondence holds. As we see, the second component of morality also is in direct relationship with the teaching of mathematics.

Finally, - humanity. Alexandrov wrote:

The moral teachings, especially Christianity, have put forward as a general principle the love and service to others. However, in many cases, this is not enough, because you need to under- stand what people need, what need this person. Loving mother could harm their children, thinking that make better for them (the most, we can say, a common situation). Similarly, people with the best intentions can produce health tips with- out having to understand or, say, feed the hungry, bring it to death....

People always judge what is happening, about other people, their actions, and often make their judgments, their sentences. But any such judgment could be justice, morality, only if it receives sufficient objective justification.

Thus, the third component of morality also is directly related to the traits of the personality formed and developed in the process of mathematics teaching. So, all three components of morality are directly connected with the need of proofs which is formed and developed in the process of mathematics teaching.

At last let us clarify

\section{Why DO We CALl OUR CONCEPTION HUMANIT ARIANLY ORIENTED?}

Return to the example with Tomas Hobbes. The influence we see in that example is truly humanitarian in character. Moreover, there are no other educational disciplines which can be compared with mathematics in this relation. So, Mathematics is the only truly humanitarian educational discipline.

It was clear to all until the end of nineteenth century when has happened what Charles Percy Snow called tragic split of culture. But this is another story.

\section{APPENDIX}

Let me add the following remarkable words of Albert

Schweitzer [10]:

Our age has a kind of artistic prejudice against a reflective theory of the universe. We are still children of the Romantic movement to a greater extent than we realize. What that movement produced in opposition to the Aufklärung and to rationalism seems to us valid for all ages against any theory that would found itself solely on thought. In such a theory of the universe we can see beforehand the world dominated by a barren intellectualism, convictions governed by mere utility, and a shallow optimism, which together throw a wet blanket over all human genius and enthusiasm.
In a great deal of the opposition which it offered to rationalis $m$ the reaction of the early nineteenth century was right. Nevertheless it remains true that it despised and distorted what was, in spite of all its imperfections, the greatest and most valuable manifestation of the spiritual life of man that the world has yet seen. Down through all circles of cultured and uncultured alike there prevailed at that time a belief in thought and a reverence for truth. For that reason alone that age stands higher than any which preceded it, and much higher than our own.

At no price must the feelings and phrases of Romanticis $m$ be allowed to prevent our generation from forming a clear conception of what reason really is. It is no dry intellectualism which would suppress all the manifold movements of our inner life, but the totality of all the functions of our spirit in their living action and interaction. In it our intellect and our will hold that mysterious intercourse which deter- mines the character of our spiritual being. These fundamental ideas which it produces contain all that we can feel or imagine about our destiny and that of mankind, and give our whole being its direction and its value....

Rationalism is more than a movement of thought which realized itself at the end of the eighteenth and the beginning of the nineteenth centuries. It is a necessary phenomenon in all normal spiritual life.

All real progress in the world is in the last analys is produced by rationalism.

And in another place [11]:

With its disdain for thinking,

our generation has lost its feeling for sincerity.

It can therefore be helped only by reviving the voice of thought.

This was written in 1923 (1998 is the year of reprint); it seems that it is written today!

\section{REFERENCES}

[1] Aichinger, I. (1955). The bound man, and other stories. London: Secker \& Warburg.

[2] Aleksandrov, A. D. (1988). Problemy nauki i pozitsiya uchenogo. (Russian). Leningrad: Nauka, Leningrad. Otdel.

[3] Aubrey, J. (1960). A brief life of Thomas Hobbes. In O. L. Dick (Ed.), Brief lives. Oxford: Oxford University Press.

[4] Bourbaki, N. (1957). Eléments de mathématique, Livre I, Théories des ensembles. Hermann.

[5] Cassiodorus, F. M. A. (1979 (first edition 562)). Institutiones. University of California Press. Retrieved from http://individual.utoronto.ca/pking/resources/ cassiodorus/institutiones.txt

[6] Dick, O. L. (Ed.). (1960). Brief lives. Oxford: Oxford University Press.

[7] Hegel, G. W. F. (1986). Philosophical propaedeutic. Oxford and New York: Basil Blackwell Ltd.

[8] Kolmogorov, A. N. (1954). Mathematics. (Russian). In The Great Soviet Encyclopedy (Vol. 26). Moscow: State Scientific Publishing "Great Soviet Encyclopedy".

[9] Polya, G. (1981). Mathematical discovery. New York \& Chichester \& Brisbane and Toronto: John Wiley \& Sons. 
[10] Schweitzer, A. (1923). Cultural philosophy, part I. London: A\&C Black Ltd.

[11] Schweitzer, A. (1998). Out of my life and thought. Baltimore \& Maryland: The Johns Hopkins University Press.

[12] Young, J. W. A. (1920). The teaching of mathematics in elementary and secondary school. New York \& London \& Bombay \& Calcutta and Madras: Longmans \& Green and Co. 